\title{
The influence of cell size on the mechanical properties of nanocellular PMMA
}

\author{
Judith Martín-de León ${ }^{\mathrm{a}, *}$, Frederik Van Loock ${ }^{\mathrm{b}}$, Victoria Bernardo ${ }^{\mathrm{a}}$, Norman A. Fleck ${ }^{\mathrm{b}}$, \\ Miguel Ángel Rodríguez-Pérez ${ }^{\mathrm{a}}$

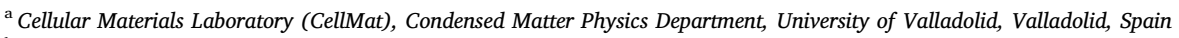 \\ ${ }^{\mathrm{b}}$ Engineering Department, University of Cambridge, Trumpington Street, CB2 1PZ, Cambridge, United Kingdom
}

H I G H L I G H T S

- The mechanical response of cellular PMMA of cell size below $50 \mathrm{~nm}$ has been measured.

- Reducing the cell size from the micro to the nanoscale does not affect the Young's modulus.

- Reducing the cell size from the micro to the nanoscale does not affect the yield strength.

- The fracture toughness (for a given density) increases when the cell size transitions from the micrometric to the nanometric range.

\section{A R T I C L E I N F O}

\section{Keywords:}

Mechanical properties

Nanocellular polymer

PMMA

\begin{abstract}
A B S T R A C T
Solid-state foaming experiments are conducted on three grades of polymethyl methacrylate (PMMA). Nanocellular PMMA foams are manufactured with an average cell size ranging from $20 \mathrm{~nm}$ to $84 \mathrm{~nm}$ and a relative density between 0.37 and 0.5 . For benchmarking purposes, additional microcellular PMMA foams with an average cell size close to $1 \mu \mathrm{m}$ and relative density close to that of the nanocellular foams are manufactured. Uniaxial compression tests and single edge notch bend tests are conducted on the PMMA foams. The measured Young's modulus and yield strength of the PMMA foams are independent of cell size whereas the fracture toughness of the PMMA foam increases with decreasing average cell size from the micron range to the nanometer range.
\end{abstract}

\section{Introduction}

Polymeric foams occupy a unique regime of material property space [1], and consequently are attractive candidates for a wide range of applications in the automotive, aerospace, and construction industry [2]. Most commercially available polymeric foams are produced by liquid foaming process such as extrusion foaming or injection moulding. However, solid-state foaming or gas dissolution foaming can be employed to produce microcellular foams, of cell size on the order of $1 \mu \mathrm{m}-10 \mu \mathrm{m}$ [3]. Microcellular foams offer a 10\%-30\% weight reduction compared to conventional macrocellular foams of identical tensile strength and impact resistance and are used in niche applications such as the soles of running shoes and in automobile interior parts $[4,5]$.

The continued development of solid-state foaming has allowed researchers to produce nanocellular foams, that is -foams, with an average cell size in the nanometric range $[6,7]$. It has been suggested that this relatively new class of porous polymers may exhibit superior mechanical and thermal properties per unit mass compared to micro- or macrocellular foams [8]. Both experimental and theoretical studies have confirmed the superior thermal insulation capability of nanocellular foams by exploitation of the Knudsen effect $[9,10]$. In contrast, only a few studies report the mechanical properties of nanocellular foams in comparison to microcellular and conventional macrocellular foams. Miller and Kumar performed uniaxial tensile tests on nanocellular and microcellular polyetherimide (PEI) foams of identical relative densities [11]. They found that PEI nanocellular foams have an increased tensile failure strength and failure strain compared to their microcellular counterparts, whereas the measured Young's modulus was independent of cell size. Sharudin and Ohshima [12] reported that the tensile yield strength of polypropylene-based (PP) nanocellular foams, of relative density $0.5-0.8$, is close to that of the solid parent polymer; however, the tensile failure strain of the nanocellular foam

\footnotetext{
* Corresponding author.

E-mail address: jmadeleon@fmc.uva.es (J. Martín-de León).
} 
was less than that of the solid polymer. Notario et al. [13] found the Charpy impact energy of a polymethyl methacrylate (PMMA) nanocellular foam exceeds that of a microcellular PMMA foam. They attributed this to the fact that the average size of the cell walls between the nano-sized cells is in the order of the size of the individual PMMA chains. Guo [14] conducted uniaxial tensile tests on polycarbonate (PC) nanocellular and microcellular foams and demonstrated that the Young's modulus and tensile ductility are independent of cell size, whereas the yield strength increases with diminishing cell size for a fixed value of relative density. Bernardo et al. [15] found that the Young's modulus, yield strength and fracture toughness of nanocellular composites made from PMMA and sepiolite particles were dependent upon the concentration and the dispersion of the particles, but independent of cell size.

In broad terms, data on the mechanical properties of nanocellular materials are limited. In particular, the mechanical properties of nanocellular PMMA of cell size below $50 \mathrm{~nm}$ have not yet been reported. In the present study, nanocellular PMMA foams are produced with an average cell size ranging from $20 \mathrm{~nm}$ to $84 \mathrm{~nm}$ and a relative density between 0.37 and 0.5. Additional microcellular PMMA foams are manufactured with relative densities close to the relative density of the nanocellular foams. Uniaxial compression and single edge notch bend tests are conducted on the nanocellular and microcellular foams to obtain the Young's modulus $E$, yield strength $\sigma_{\mathrm{y}}$, and fracture toughness $K_{\mathrm{Ic}}$. The dependence of $E, \sigma_{\mathrm{y}}$, and $K_{\mathrm{Ic}}$ upon cell size and relative density is presented and discussed.

\section{Materials and methods}

\subsection{Materials}

Solid-state foaming experiments are conducted on three PMMA grades: V 825T, $7 \mathrm{~N}$, and $6 \mathrm{~N}$. V 825T was provided in the form of pellets from ALTUGLAS ${ }^{\circledR}$ International (Colombes, France), while $7 \mathrm{~N}$ and $6 \mathrm{~N}$ are provided in the form of pellets from PEXIGLAS ${ }^{\circledast}$ Evonik Industries (Essen, Germany). The three grades have a density $\rho_{\mathrm{s}}$ equal to $1190 \mathrm{~kg} \mathrm{~m}^{-3}$ (as measured at $23^{\circ} \mathrm{C}$ and at $50 \%$ relative humidity). The zero-shear viscosity $\eta_{0}$ (as measured by shear rheology, see section 2.4.4 below), and the glass transition temperature $T_{\mathrm{g}}$ (as measured by differential scanning calorimetry (DSC), see section 2.4.3 below) of the PMMA grades are summarized in Table 1. V 825T will be named as high viscosity PMMA (HV), $7 \mathrm{~N}$ as medium viscosity (MV) and $6 \mathrm{~N}$ as low viscosity PMMA (LV).

\subsection{Production of the foaming precursors}

The PMMA pellets were first dried at $80^{\circ} \mathrm{C}$ for $4 \mathrm{~h}$ to remove remnant moisture. Then, the pellets were made molten by heating them up to $250{ }^{\circ} \mathrm{C}$ in a hot press for $600 \mathrm{~s}$. Next, the pellets were compacted at a pressure equal to $42 \mathrm{MPa}$ and a temperature of $250{ }^{\circ} \mathrm{C}$ for $60 \mathrm{~s}$. The resulting sheets were cooled to room temperature with the pressure of $42 \mathrm{MPa}$ maintained. Cuboid-shaped foaming precursor samples of dimensions $68 \times 13 \times 4 \mathrm{~mm}^{3}$ were machined from the compression moulded sheets.

Table 1

Measured properties of the three PMMA grades used in this study.

\begin{tabular}{lll}
\hline Material & $\eta_{0}(\mathrm{~Pa} \cdot \mathrm{s})$ & $\mathrm{T}_{\mathrm{g}}\left({ }^{\circ} \mathrm{C}\right)$ \\
\hline V 825T (HV) & 7100 & 114.5 \\
$7 \mathrm{~N}(\mathrm{MV})$ & 3800 & 109.3 \\
6 N (LV) & 1590 & 98.6 \\
\hline
\end{tabular}

\subsection{Gas dissolution foaming experiments}

Foaming experiments on the HV, MV and LV PMMA grades were performed using a pressure vessel (model PARR 4681) provided by Parr Instrument Company (Moline, IL, USA). The system has a pressure controller model SFT-10, provided by Parr Instrument Company (Moline, IL, USA) and a temperature controller (CAL 3300). Medical grade $\mathrm{CO}_{2}$ (>99.9\% purity) was used as the blowing agent for the foaming tests. A two-step solid-state foaming process was employed, as detailed in Martín-de Leon et al. [16]. The precursor samples were held in the pressure vessel at a constant $\mathrm{CO}_{2}$ saturation pressure $p_{\text {sat }}$ equal to $31 \mathrm{MPa}$, and at a constant saturation temperature $T_{\text {sat }}$ equal to $25^{\circ} \mathrm{C}$ for $24 \mathrm{~h}$ in order to ensure saturation of the $\mathrm{CO}_{2}$ within the PMMA. Additional foaming tests were conducted by saturating the PMMA precursor samples in a pressure vessel (model PARR 4760), provided by Parr Instrument Company (Moline, IL, USA), and placed inside a freezer. Saturation experiments were done at constant $T_{\text {sat }}$ ranging from $-15^{\circ} \mathrm{C}$ to $-32{ }^{\circ} \mathrm{C}$ and a constant $p_{\text {sat }}$ ranging from $6 \mathrm{MPa}$ to $31 \mathrm{MPa}$. After saturation, the pressure was rapidly released to atmospheric pressure with an instantaneous pressure drop rate close to $100 \mathrm{MPa} \mathrm{s}^{-1}$ for the samples saturated at $T_{\text {sat }}=25^{\circ} \mathrm{C}$ and $p_{\text {sat }}=31 \mathrm{MPa}$, whereas a pressure drop rate of $10 \mathrm{MPa} \mathrm{s}^{-1}$ to $70 \mathrm{MPa} \mathrm{s}^{-1}$ for all other saturation conditions. The samples were then foamed in a hot press (Remtex, Barcelona) at a foaming temperature equal to $60^{\circ} \mathrm{C}$ for a foaming time close to $60 \mathrm{~s}$, resulting in flat foamed samples suitable for mechanical testing [17].

\subsection{Characterization techniques}

\subsubsection{Density}

The density of the solid precursors $\rho_{\mathrm{s}}$ was measured through pycnometry using a gas pycnometer (Mod. AccuPyc II 1340, Micromeritics, Norcross, GA, USA). In contrast, the density of the foams $\rho_{f}$ was measured with the water displacement-based density determination kit of an AT261 Mettler-Toledo balance. A surface layer of depth $200 \mu \mathrm{m}$ was removed by polishing to ensure that the solid skin (of thickness well below $100 \mu \mathrm{m}$ ) was absent before the density measurements on the foams were made. All the testing, including the measurement of the mechanical properties, was performed in samples in which the solid skin was removed. The relative density of each sample $\rho_{\mathrm{r}}$ was determined via:

$\rho_{\mathrm{r}}=\frac{\rho_{\mathrm{f}}}{\rho_{\mathrm{s}}}$

\subsubsection{Cellular structure}

Foam samples were fractured in liquid nitrogen and coated with a layer of gold of $5 \mathrm{~nm}$ thickness by a sputter coater (model SDC 005, Balzers Union, Balzers, Liechtenstein). Micrographs of the coated fracture surfaces were obtained by a scanning electron microscope (QUANTA 200 FEG, Hillsboro, OR, USA). SEM micrographs were analysed by using a developed in-house software based on ImageJ/FIJI [18]. The cell size $\varphi$ and the cell nucleation density $N_{0}$ (as calculated via the method of Kumar [19]) were measured for each foam sample. The homogeneity of the produced samples was determined by inspection of the SEM micrographs across the thickness of the cellular material (see section 1 of supporting information for additional details). More than 200 cells were considered, from multiple micrographs per foam sample, to obtain quantitative values of the cellular structure characteristics (see section 2 of supporting information for further details).

\subsubsection{Glass transition temperature}

The glass transition temperature $T_{\mathrm{g}}$ of the as-foamed and solid samples was measured by differential scanning calorimetry DSC (Mettler DSC3 differential-scanning calorimeter). To achieve this, samples of mass $5 \mathrm{mg}$ were machined from the foam blocks and heated from $\mathrm{T}=20^{\circ} \mathrm{C}$ to $\mathrm{T}=160^{\circ} \mathrm{C}$ at $0.17^{\circ} \mathrm{C} \mathrm{s}^{-1}$. The value for $T_{\mathrm{g}}$ was 


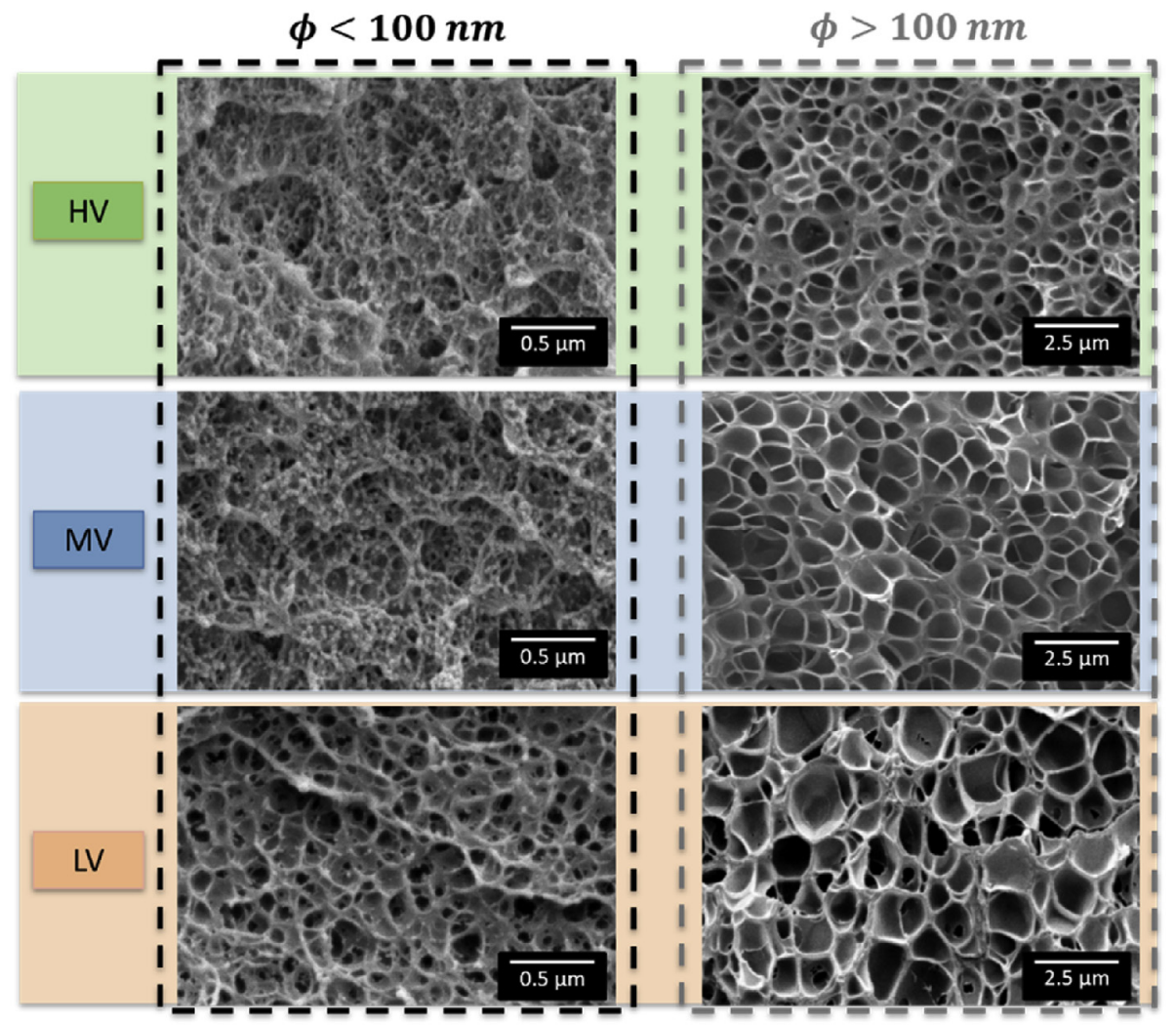

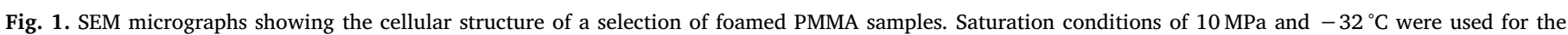
samples with cell sizes below $100 \mathrm{~nm} ; 30 \mathrm{MPa}$ and $24^{\circ} \mathrm{C}$ were used for the samples with cell sizes above $100 \mathrm{~nm}$.

identified as the mid-point of the observed transition on the heat flow versus temperature curve. The difference between the measured glass transition temperature $T_{\mathrm{g}, \mathrm{f}}$ of a foam sample made from a given PMMA grade and the measured glass transition temperature $T_{\mathrm{g}, \mathrm{s}}$ of the solid PMMA precursor of the same grade is written as:

$\Delta T_{\mathrm{g}}=T_{\mathrm{g}, \mathrm{f}}-T_{\mathrm{g}, \mathrm{s}}$

\subsubsection{Polymers rheology}

The zero-shear viscosity $\eta_{0}$ of the used polymers was measured by shear rheology in a stress-controlled rheometer, (AR 2000 EX from TA instruments). Solid cylindrical samples were prepared by compression moulding as explained in section 2.2. Dynamic shear viscosity measurements were performed with a parallel plates geometry of $\mathrm{R}=25 \mathrm{~mm}$ and a fixed gap of $\mathrm{h}=1 \mathrm{~mm}$ at a temperature of $230{ }^{\circ} \mathrm{C}$ in a nitrogen atmosphere. The angular frequency $\omega$ ranged between 0.01 $\mathrm{s}^{-1}$ and $100 \mathrm{~s}^{-1}$, and measurements were conducted at a shear strain equal to 0.06 . The value of the zero shear viscosity was taken as the value of the complex viscosity at low frequencies in the Newtonian plateau [20].

\subsubsection{Open cell content}

The open cell content of the foamed samples was measured by gas pycnometry (Mod. AccuPyc II 1340, Micromeritics) with nitrogen in accordance with the ASTM D6226-15 standard [22]. The open cell content ratio $\left(O_{\mathrm{v}}\right)$, is defined as the ratio of the volume of open cells to the total cell volume of a foam, and is given by:

$O_{\mathrm{v}}=\frac{V-V_{\mathrm{p}}-V_{\mathrm{s}}}{V\left(1-\rho_{\mathrm{r}}\right)}$

where $V$ is the geometric volume of the sample, as determined via the water-displacement method, $V_{\mathrm{p}}$ is the volume determined by the pycnometer and $V_{\mathrm{s}}$ corresponds to the value of the volume of the exposed cells at the surface of the sample; $V_{\mathrm{s}}$ is assumed to be negligible for the microcellular and nanocellular foams. The value for $V_{\mathrm{p}}$. is obtained via a pressure scan in the pycnometer from $0.2 \mathrm{MPa}$ to $1.3 \mathrm{MPa}$. The resulting pycnometric volume versus pressure curve becomes close to independent of pressure when the open, interconnected pores in the foam are completely filled with gas. The pressure-independent value for the pycnometric volume is taken as $V_{\mathrm{p}}$ to calculate $O_{\mathrm{v}}$ via Eq. (3).

\subsubsection{Mechanical tests}

Uniaxial compression tests were conducted on the solid and foamed PMMA. Compression specimens of dimensions $10 \times 10 \times 4 \mathrm{~mm}^{3}$ were machined from each foamed and solid sample. At least three compression tests are performed for each foamed sample and solid PMMA grade. The compression tests were conducted on a screw-driven test bench (Instron 5584 electromechanical testing machine) at room temperature. The samples were compressed in a direction perpendicularly to the compression moulding direction of the PMMA sheets prior to foaming and with a cross-head speed equal to $0.083 \mathrm{~mm} \mathrm{~s}^{-1}$, resulting in a strain rate equal to $8.3 \times 10^{-4} \mathrm{~s}^{-1}$ for all compression tests. The displacement of the material elements along the compression direction was measured with a laser extensometer.

Single edge notch three point bending (SENB) tests were performed at room temperature with a screw-driven test bench at a constant crosshead speed of $0.167 \mathrm{~mm} \mathrm{~s}^{-1}$. Singe edge notch bend specimens were cuboids with in-plane dimensions $60 \times 13.6 \mathrm{~mm}^{2}$ and thickness close to $4 \mathrm{~mm}$. A sharp pre-crack was made at the end of a sawed notch by tapping with a razor blade. At least 6 specimens were tested for each PMMA grade and each foamed sample (that means for each cell size and relative density, at least six experiments were performed). Given measurements in the paper correspond to the mean value of those 6 experiments and their standard deviation. The critical mode I stress intensity factor $K_{\text {Ic }}$ was calculated as a measure for the fracture toughness in accordance with the ASTM D5045-14 standard [21]. 
Prior to all the experiments the samples were dried overnight at $60{ }^{\circ} \mathrm{C}$ to remove the moisture and reduce internal stresses.

\section{Results}

\subsection{Cellular materials characterization}

A representative set of SEM micrographs of the nanocellular foams made from the three PMMA grades are shown in Fig. 1. Additional micrographs for the microcellular foams are included. The foamed samples were found to have a homogeneous morphology (see section 1 of supporting information for further information).

The samples which were saturated at room temperature during the foaming tests resulted in foams with an average cell size exceeding $100 \mathrm{~nm}$ and with a cell nucleation density around $10^{12}$ to $10^{13}$ nuclei/ $\mathrm{cm}^{3}$, while saturation at temperatures below $0{ }^{\circ} \mathrm{C}$ resulted in nanocellular materials with an average void size below $100 \mathrm{~nm}$ and cell nucleation densities ranging $10^{15}-10^{16}$ nuclei $/ \mathrm{cm}^{3}$. These results are consistent with the observation of Martín-de León et al. [22] who found that saturation temperatures below $0{ }^{\circ} \mathrm{C}$ lead to a $\mathrm{CO}_{2}$ solubility above $40 \mathrm{wt} \%$ and nanocellular materials with cell size close to $50 \mathrm{~nm}$ and cell nucleation density close to $10^{16} \mathrm{nuclei} / \mathrm{cm}^{3}$. In contrast, saturating PMMA at room temperature with a $\mathrm{CO}_{2}$ pressure equal to $30 \mathrm{MPa}$ results in a $\mathrm{CO}_{2}$ solubility close to $31 \mathrm{wt} \%$, and cellular materials with cell sizes above $100 \mathrm{~nm}[22,23]$. The observed differences between the cellular materials made from the different PMMA grades when subjected to identical saturation and foaming conditions can be attributed to the different zero shear viscosity of the grades [22].

The measured average cell size $\varphi$ of the produced nanocellular and microcellular foams is plotted as a function of the measured relative density $\rho$ in Fig. 2. Nanocellular foams with cell size between $20 \mathrm{~nm}$ and $84 \mathrm{~nm}$ and of relative density between 0.37 and 0.53 were produced from the three PMMA grades. In addition, microcellular foams of each grade were manufactured with an average cell size in the order of $1 \mu \mathrm{m}$ and relative density close to the relative density of the nanocellular foams. Contours of equal values for the open cell content are included in the cell size versus relative density plot shown in Fig. 2a. The microcellular foams are predominantly closed-celled in nature in within the explored range of relative densities in this study, whereas the nanocellular foams are open-celled. In addition, contours of equal values for the difference in glass transition temperature $\Delta T_{\mathrm{g}}$ are plotted on the cell size versus relative density diagram shown in Fig. $2 \mathrm{~b}$. The value of $\Delta T_{\mathrm{g}}$ increases with decreasing value of cell size and, as demonstrated by Martin-de León [23], the value of $\Delta T_{\mathrm{g}}$ may be used as a measure for the confinement of the solid material separating the micro- or nano-sized

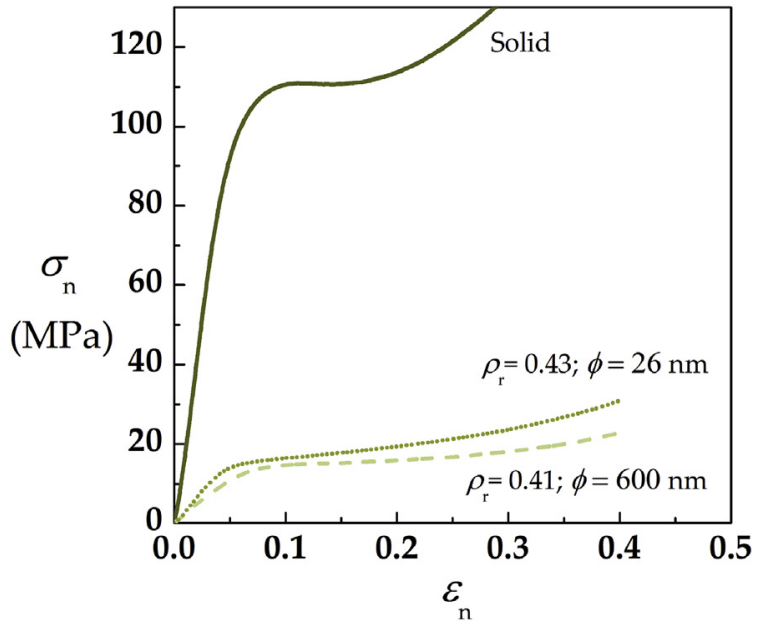

Fig. 3. A representative set of nominal stress versus nominal strain curves for the V825T solid and the foamed PMMA. Experiments were terminated at a nominal strain close to 0.4 .

voids.

\subsection{Mechanical properties}

\subsubsection{Stress-strain curves}

A nominal stress $\sigma_{\mathrm{n}}$ versus nominal strain $\varepsilon_{\mathrm{n}}$ curve for the solid PMMA HV in uniaxial compression is shown in Fig. 3. Representative $\sigma_{\mathrm{n}}$ - $\varepsilon_{\mathrm{n}}$ curves for the microcellular and nanocellular HV foams of close to identical relative density are included in Fig. 3.

The structural response of the solid and foamed samples of the three grades is similar. There is an initial linear, elastic region until the yield point, after which a small degree of softening occurs [24]. Softening is followed by a plateau in stress and subsequent hardening [1]. The compression tests were terminated at a nominal strain close to 0.4 ; no specimen failure was observed prior to completion of the tests. The elastic modulus $E$ was calculated from the slope of the initial linear region, while the compressive yield strength $\sigma_{\mathrm{y}}$ was deduced from the peak load before the plateau in stress is observed.

\subsubsection{Mechanical properties of the solid PMMA grades}

The Young's modulus of the solid PMMA grades was found to be close to $2.2 \mathrm{GPa}$ (and observed to be independent of material grade). The value for the fracture toughness, as obtained via the SENB tests, is
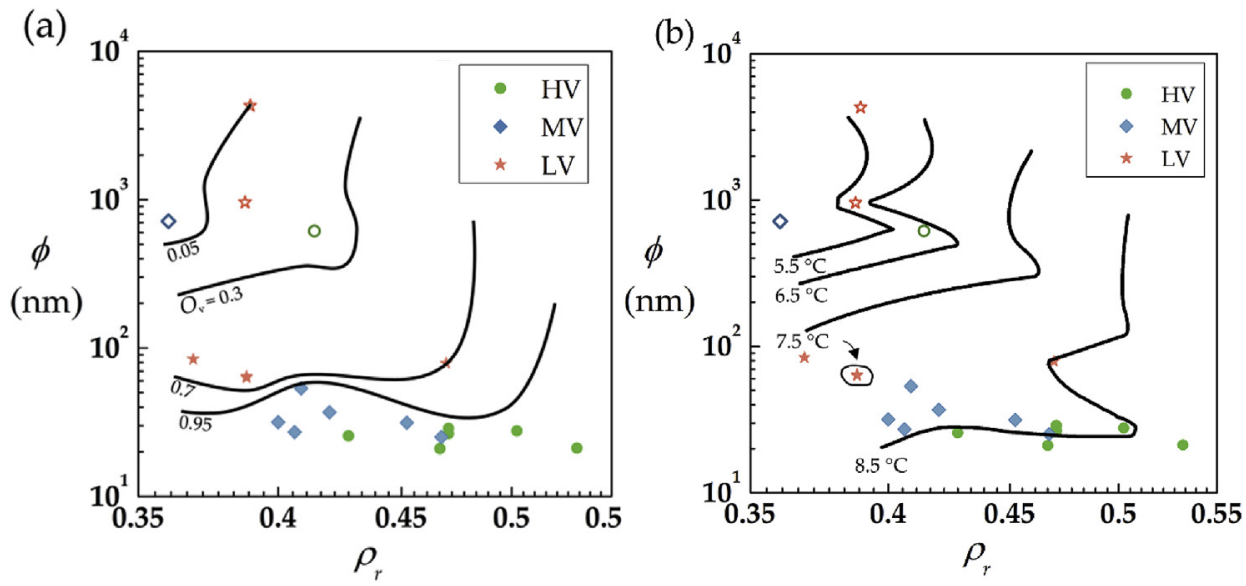

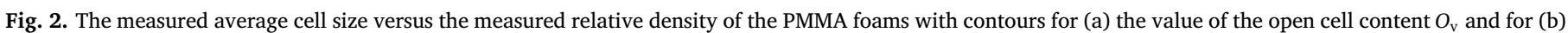

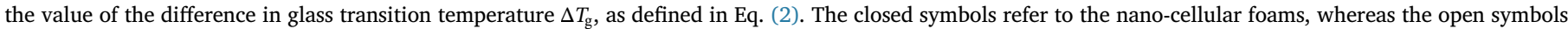
denote the microcellular foams. (The contour plots were constructed via the grid data and contour functions in Matlab). 


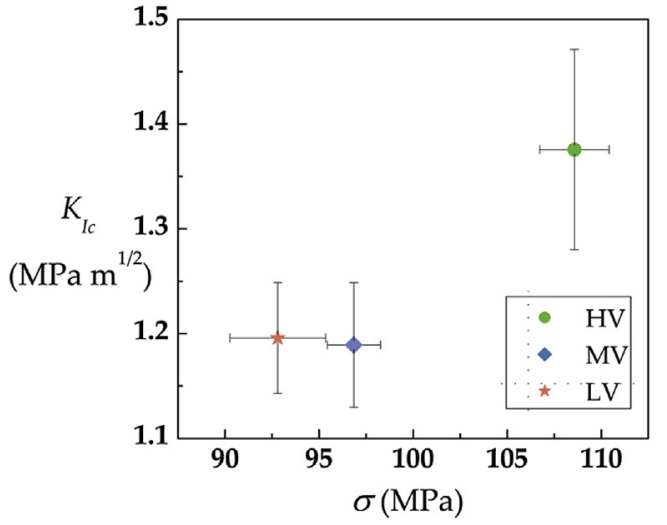

Fig. 4. The measured fracture toughness versus yield strength of the three PMMA grades. The error bars correspond to an uncertainty level of one standard deviation.

plotted versus the measured value of the yield strength in Fig. 4. The value for the yield strength and the fracture toughness of the MV and LV grades are close to identical, whereas the yield strength (and fracture toughness) of the HV grade was found to be close to $20 \%$ higher than that of the MV and LV grades. This may be attributed to the measured higher glass transition temperature of the HV grade compared to the MV and LV grades, see Table 1 [24].

\subsubsection{Mechanical properties of the PMMA foams}

The measured values of $\mathrm{E}, \sigma_{\mathrm{y}}$, and $K_{\mathrm{Ic}}$ for each foamed sample made from a given PMMA grade were normalised with respect to the values for $\mathrm{E}, \sigma_{\mathrm{y}}$, and $K_{\mathrm{Ic}}$ of the solid materials of the same grade:

$E_{\mathrm{r}}=\frac{E_{\mathrm{f}}}{E_{\mathrm{s}}}$

$\sigma_{\mathrm{y}, \mathrm{r}}=\frac{\sigma_{\mathrm{y}, \mathrm{f}}}{\sigma_{\mathrm{y}, \mathrm{s}}}$

$K_{\mathrm{Ic}, \mathrm{r}}=\frac{K_{\mathrm{Ic}, \mathrm{f}}}{K_{\mathrm{Ic}, \mathrm{s}}}$

where $E_{\mathrm{r}}, \sigma_{\mathrm{y}, \mathrm{r}}$ and $K_{\mathrm{Ic}, \mathrm{r}}$ are the relative Young's modulus, yield strength and fracture toughness of a foam respectively, $E_{\mathrm{f}}, \sigma_{\mathrm{y}, \mathrm{f}}$ and $K_{\mathrm{Ic}, \mathrm{f}}$ are the measured properties of the foams and $E_{\mathrm{s}}, \sigma_{\mathrm{y}, \mathrm{s}}$ and $K_{\mathrm{Ic}, \mathrm{s}}$ are the properties of the solid PMMA. Note that data from a previous work [15] are examined in this section too in order to extend the relative density range of the microcellular PMMA; the microcellular PMMA materials considered in this work have an average cell size ranging from $3.2 \mu \mathrm{m}$ to $4.3 \mu \mathrm{m}$ and relative density ranging from 0.29 to 0.52 .

The measured values for the relative modulus $E_{\mathrm{r}}$ and for the relative yield strength $\sigma_{\mathrm{y}}$ of the nanocellular and microcellular PMMA foams are plotted as a function of the measured relative density in Fig. 5a and b, respectively. The values of $E_{\mathrm{r}}$ and $\sigma_{\mathrm{y}}$ are found to be independent of cell size within the explored range of relative density and cell size.

According to the model of Gibson and Ashby, the relative modulus of open-celled foams scales with the relative density as follows [25]:

$E_{\mathrm{r}}=C_{1} \rho_{\mathrm{r}}^{2}$

Gibson and Ashby fitted Eq. (7) to data for open-celled polymeric foams in the literature in a wide range of cell sizes and relative densities between 0.01 and 1 . They suggested that the value for the fitting constant $\mathrm{C}_{1}$, by considering those ranges of materials, equals unity. The $E_{\mathrm{r}}$ versus $\rho_{\mathrm{r}}$ curve predicted by Eq. (7) is plotted in Fig. 5a assuming $\mathrm{C}_{1}=1$. The slope of the measured $E_{\mathrm{r}}$ versus $\rho_{\mathrm{r}}$ curve. Equation (7) is fitted to the measured $E_{\mathrm{r}}$ versus $\rho_{\mathrm{r}}$ curve, resulting in $\mathrm{C}_{1}=0.7$. The predicted $E_{\mathrm{r}}$ versus $\rho_{\mathrm{r}}$ curve by Eq. (7) with $\mathrm{C}_{1}=0.7$ is included in Fig. 5a.
Likewise, the relative yield strength of open-celled foams scales with the relative density as follows [25]:

$\sigma_{\mathrm{y}, \mathrm{r}}=C_{2} \rho_{\mathrm{r}}^{\frac{3}{2}}$

where $\mathrm{C}_{2}$ is a constant of proportionality equal to 0.3 as suggested by Gibson and Ashby, when considering a wide range of cell sizes and relative densities from 0.05 to 0.5 . The predicted $\sigma_{\mathrm{y}, \mathrm{r}}$ versus $\rho_{\mathrm{r}}$ curve by Eq. (8) by assuming $C_{2}=0.3$ is shown in Fig. 5b. Equation (8) is fitted to the measured $\sigma_{\mathrm{y}, \mathrm{r}}$ data, resulting in $\mathrm{C}_{2}=0.47$ for the relative density range considered in this work. The predicted $\sigma_{\mathrm{y}, \mathrm{r}}$ versus $\rho_{\mathrm{r}}$ curve by Eq. (8) with $C_{2}=47$ is included in Fig. 5. It is emphasised that the slopes of the measured relative modulus versus relative density and relative strength versus relative density curves are in good agreement with those given in Eqs. (7) and (8), respectively.

The measured relative fracture toughness $K_{\mathrm{Ic}, \mathrm{r}}$ of the nanocellular and microcellular PMMA foams is plotted as a function of the measured relative density in Fig. $6 \mathrm{a}$. The measured values for $K_{\mathrm{Ic}, \mathrm{r}}$ of the microcellular foams are lower than those of the nanocellular foams with close to identical relative density. Hence, we deduce that, within the explored range of relative density, the relative fracture toughness increases when the average cell size of the PMMA foams decreases from the micro-sized range to the nano-sized range: a cell size effect is observed.

The model of Maiti and Ashby [26] may be used to predict the normalised fracture toughness of open-celled foams as a function of relative density:

$\bar{K}_{\mathrm{Ic}}=\frac{K_{\mathrm{Ic}}}{\sigma_{\mathrm{y}, \mathrm{s}} \sqrt{\pi \varphi}}=C_{3} \rho_{\mathrm{r}}^{\frac{3}{2}}$

where $C_{3}$ is equal to 0.65 according to the work of Maiti and Ashby [26]. The measured values for the normalised fracture toughness of the PMMA foams is shown in Fig. 6b. Reported values for $\bar{K}_{\text {Ic }}$ in the literature for macrocellular and microcellular polymeric foams are plotted as a function of relative density in Fig. $6 \mathrm{~b}$ [4,27-31]. The $\bar{K}_{\mathrm{Ic}}$ versus $\rho_{\mathrm{r}}$ curve of the macrocellular data is well approximated by Eq. (9) taking $\mathrm{C}_{3}=0.65$. The slope of the nanocellular and microcellular $\bar{K}_{\text {Ic }}$ versus $\rho_{\mathrm{r}}$ curve is in agreement with the slope predicted by Eq. (9). As a result of the observed cell size effect, the value for $C_{3}$ is found to be a function of cell size: the measured $\bar{K}_{\text {Ic }}$ versus $\rho_{\mathrm{r}}$ curve for the microcellular and nanocellular PMMA foams is predicted with reasonable accuracy via Eq. (9) by assuming $C_{3}=11$ and $C_{3}=69$, respectively.

\section{Conclusions}

Nanocellular and microcellular foams are manufactured from three different grades of PMMA via the solid-state foaming route. The relative density of the foams ranges between 0.37 and 0.5 . Uniaxial compression tests and single edge notch bend tests are conducted on the foams and the solid PMMA. The measured values of the Young's modulus, yield strength, and fracture toughness of the foams were normalised with respect to the measured values of the solid PMMA grades. The relative fracture toughness was found to be dependent upon cell size: the relative fracture toughness of a foam of a given relative density increases when the average void size decreases from the micro-sized range to the nano-sized range. In contrast, no dependence of the relative Young's modulus and the relative yield strength upon cell size was observed within the explored range of relative density and cell size.

\section{Acknowledgements}

Financial assistance from MINECO, FEDER, UE (MAT2015-69234R), the Junta of Castile and Leon (VA275P18) and Spanish Ministry of Science, Innovation and Universities (RTI2018-098749-B-I00) are gratefully acknowledged. Financial support from FPU grant FPU14/ 02050 (V. Bernardo) from the Spanish Ministry of Education and Junta of Castile and Leon grant (J. Martín-de León) are gratefully 

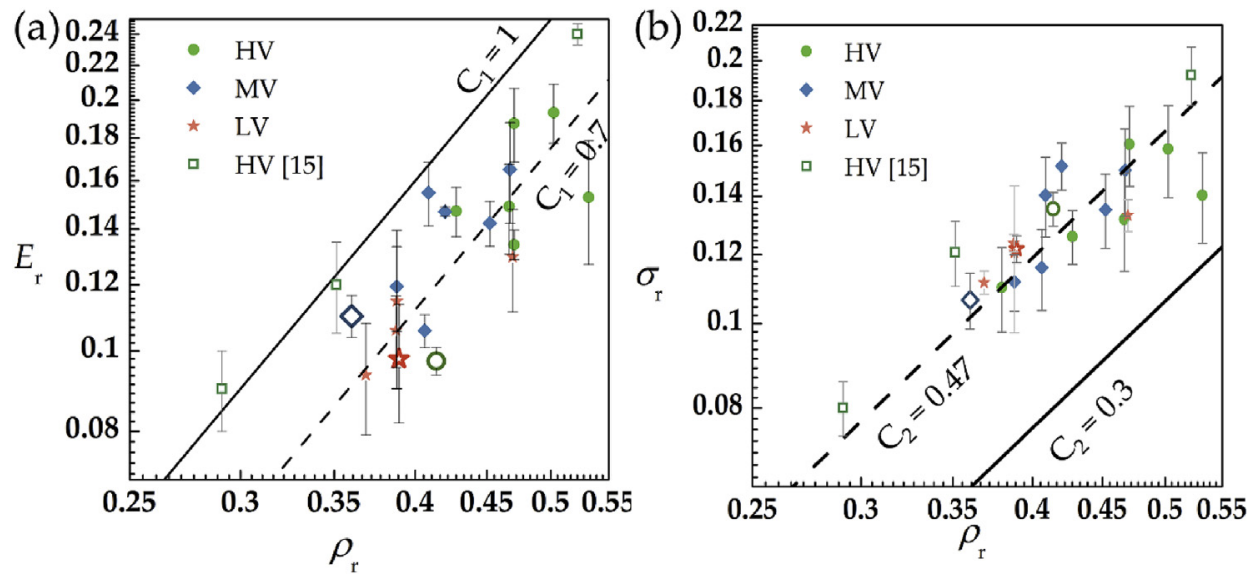

Fig. 5. (a) The measured relative Young's modulus $E_{\mathrm{r}}$ as a function of the relative density $\rho_{\mathrm{r}}$ and(b) the measured relative yield strength $\sigma_{\mathrm{y}}$ as a function of the relative density. The closed symbols refer to the nanocellular foams $(\varphi<100 \mathrm{~nm})$, whereas the open symbols refer to the microcellular foams $(\varphi>100 \mathrm{~nm})$. The predicted $E_{\mathrm{r}}$ versus $\rho_{\mathrm{r}}$ curve by Eq. (7) is plotted in (a) with $\mathrm{C}_{1}=1$ (solid line) and $\mathrm{C}_{1}=0.7$ (dashed line). The $\sigma_{\mathrm{y}, \mathrm{r}}$ versus $\rho_{\mathrm{r}}$ curve predicted by Eq. (8) is included in (b) with $\mathrm{C}_{1}=0.3$ (solid line) and $\mathrm{C}_{2}=0.47$ (dashed line).
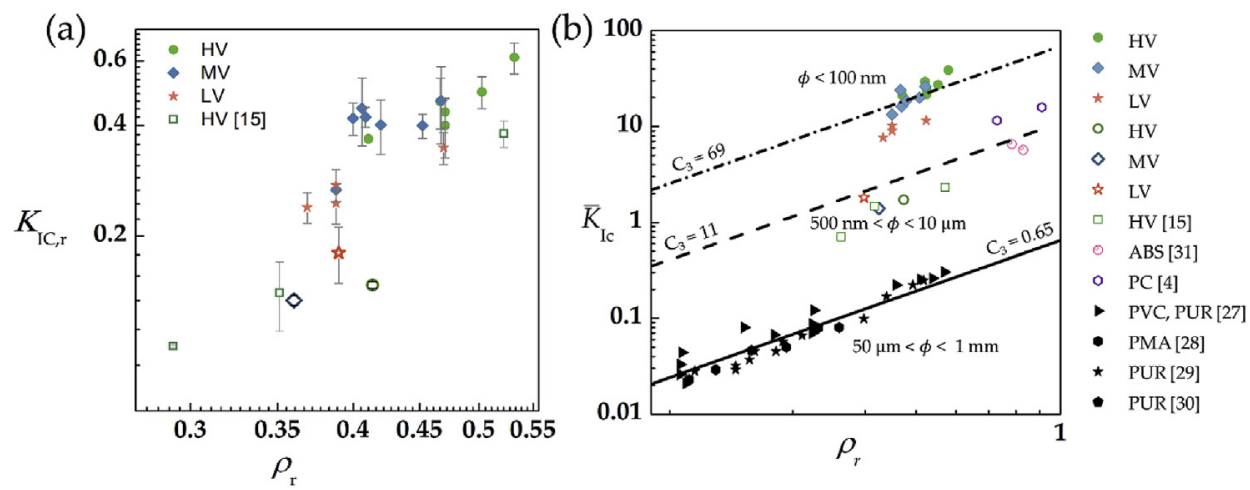

Fig. 6. (a) The measured relative fracture toughness $K_{\mathrm{Ic}, \mathrm{r}}$ as a function of the relative density $\rho_{\mathrm{r}}$. The closed symbols refer to the nanocellular foams $(\varphi<100 \mathrm{~nm})$, whereas the open symbols refer to the microcellular foams $\left(\varphi>100 \mathrm{~nm}\right.$ ). (b) The measured normalised fracture toughness $\bar{K}_{\text {Ic }}$ as a function of relative density. Reported values for $\bar{K}_{\text {Ic }}$ for macrocellular and microcellar foams in the literature are plotted as a function of relative density. The curves predicted by Eq. (9) are included for selected values of $\mathrm{C}_{3}$.

acknowledged. Financial support from SABIC and the EPSRC award 1611305 (F. Van Loock), and the ERC project MULTILAT (N. A. Fleck) are acknowledged too.

\section{Appendix A. Supplementary data}

Supplementary data to this article can be found online at https:// doi.org/10.1016/j.polymer.2019.121805.

\section{References}

[1] L.J. Gibson, M.F. Ashby, Cambridge, ed. 2nd, Cambridge University Press, United States, 1997.

[2] J.M. Buist, In Fire and Cellular Polymers, Springer, Dordrecht, 1986, pp. 5-23.

[3] V. Kumar, N.P. Suh, Polym. Eng. Sci. 30 (1990) 1323-1329.

[4] M.N. Bureau, J. Cell. Plast. 42 (2006) 229-240.

[5] H. Sun, G. Sur, J. Mark, Eur. Polym. J. 38 (2002) 2373-2381.

[6] S. Costeux, M.H. Jeon, T.S. Bunker, I. Khan, Foam. 2012 Conf. (2012) 1-6.

[7] B. Notario, J. Pinto, M.A. Rodriguez-Perez, Prog. Mater. Sci. $78-79$ (2016) 93-139.

[8] D. Schmidt, V.I. Raman, C. Egger, C. du Fresne, V. Schädler, Mater. Sci. Eng. C 27 (2007) 1487-1490.

[9] G. Wang, C. Wang, J. Zhao, G. Wang, C.B. Park, G. Zhao, Nanoscale 9 (2017) 5996-6009.

[10] B. Notario, J. Pinto, E. Solorzano, J.A. De Saja, M. Dumon, M.A. Rodriguez-Perez, Polym. (United Kingdom). 56 (2015) 57-67.
[11] K. Nadella, V. Kumar, Exp. Anal. Nano Eng. 22 (2007) 765-766.

[12] R.W.B. Sharudin, M. Ohshima, Macromol. Mater. Eng. 296 (2011) 1046-1054.

[13] B. Notario, J. Pinto, M.a. Rodriguez-Perez, Polymer 63 (2015) 116-126.

[14] H. Guo, thesis (2015).

[15] V. Bernardo, F. Loock, J. Martin-de Leon, N.A. Fleck, M.A. Rodriguez-Perez, Macromol. Mater. Eng. (2019), https://doi.org/10.1002/mame.201900041.

[16] J. Martín-de León, V. Bernardo, M.Á. Rodríguez-Pérez, Polymers 8 (2016) 265.

[17] J. Martín-de León, V. Bernardo, P. Cimavilla-Román, M. Angel, Adv. Eng. Mater. $1-8$ (2019) 1900148.

[18] J. Pinto, E. Solorzano, M.a. Rodriguez-Perez, J.A. de Saja, J. Cell. Plast. 49 (2013) $555-575$.

[19] V. Kumar, N.P. Suh, Polym. Eng. Sci. 30 (1990) 1323-1329.

[20] E. Laguna-Gutierrez, R. Van Hooghten, P. Moldenaers, M. Angel Rodriguez-Perez, J. Appl. Polym. Sci. 132 (2015) 1-12.

[21] J. ASTM Int. (2014), https://doi.org/10.1520/D5045-14.priate.

[22] J.M. León, V. Bernardo, E. Laguna-gutiérrez, M.Á. Rodríguez-pérez, Polym. Int. (2019) 1-16.

[23] J. Martín-de León, V. Bernardo, M. ángel Rodríguez-Pérez, Polymers 8 (2016), https://doi.org/10.3390/polym8070265.

[24] F. Van Loock, N.A. Fleck, Polymer 148 (2018) 259-268.

[25] M.F. Ashby, R.F.M. Medalist, Metall. Mater. Trans. A 14 (2007) 1755-1769.

[26] S.K. Maiti, M.F. Ashby, L.J. Gibson, Scr. Metall. 18 (1984) 213-217.

[27] M.E. Kabir, M.C. Saha, S. Jeelani, Mater. Sci. Eng. A 429 (2006) 225-235.

[28] S. K. Maiti, M. F. Ashby, L. J. Gibson, 18, 213-217 (1984).

[29] A. McIntyre, G.E. Anderton, Polymer 20 (1979) 247-253.

[30] C.W. Fowlkes, Int. J. Fract. 10 (1974) 99-108.

[31] J. Gómez-Monterde, M. Schulte, S. Ilijevic, J. Hain, M. Sánchez-Soto, O.O. Santana, M.L. Maspoch, J. Appl. Polym. Sci. 133 (2016) 1-10. 